OPEN ACCESS

Edited by:

Olivier Cuvillier,

Centre National de la Recherche

Scientifique (CNRS), France

Reviewed by:

François E. Paris,

University of Nantes, France

Nguyen (Nathan) T. K. Vo,

Wilfrid Laurier University, Canada

*Correspondence:

An Aerts

an.aerts@sckcen.be

Specialty section

This article was submitted to Pharmacology of Anti-Cancer Drugs,

a section of the journal

Frontiers in Pharmacology

Received: 15 May 2017

Accepted: 09 August 2017

Published: 22 September 2017

Citation:

Baselet B, Azimzadeh O,

Erbeldinger N, Bakshi MV,

Dettmering T, Janssen A, Ktitareva S, Lowe DJ, Michaux A, Quintens R,

Raj $K$, Durante $M$, Fournier $C$,

Benotmane MA, Baatout $S$

Sonveaux $P$, Tapio $S$ and Aerts $A$

(2017) Differential Impact of

Single-Dose Fe Ion and X-Ray

Irradiation on Endothelial Cell

Transcriptomic and Proteomic Responses. Front. Pharmacol. 8:570.

doi: 10.3389/fphar.2017.00570

\section{Differential Impact of Single-Dose Fe Ion and X-Ray Irradiation on Endothelial Cell Transcriptomic and Proteomic Responses}

\author{
Bjorn Baselet ${ }^{1,2}$, Omid Azimzadeh ${ }^{3}$, Nadine Erbeldinger ${ }^{4,5}$, Mayur V. Bakshi ${ }^{3}$, \\ Till Dettmering ${ }^{4}$, Ann Janssen ${ }^{1}$, Svetlana Ktitareva ${ }^{4}$, Donna J. Lowe ${ }^{6}$, Arlette Michaux ${ }^{1}$, \\ Roel Quintens ${ }^{1}$, Kenneth Raj ${ }^{6}$, Marco Durante ${ }^{4,5}$, Claudia Fournier ${ }^{4}$, \\ Mohammed A. Benotmane ${ }^{1}$, Sarah Baatout ${ }^{1,7}$, Pierre Sonveaux ${ }^{2}$, Soile Tapio ${ }^{3}$ and \\ An Aerts $^{1 *}$ \\ ${ }^{1}$ Radiobiology Unit, Institute for Environment, Health and Safety, Belgian Nuclear Research Centre (SCK•CEN), Mol, \\ Belgium, ${ }^{2}$ Pole of Pharmacology and Therapeutics, Institut de Recherche Expérimentale et Clinique, Université catholique de \\ Louvain, Brussels, Belgium, ${ }^{3}$ Institute of Radiation Biology, Helmholtz Zentrum Munich, German Research Center for \\ Environmental Health, Munich, Germany, ${ }^{4}$ GSI Helmholtz Centre for Heavy lon Research, Darmstadt, Germany, ${ }^{5}$ Technical \\ University Darmstadt, Darmstadt, Germany, ${ }^{6}$ Department of Radiation Effects, Centre for Radiation, Chemical and \\ Environmental Hazards, Public Health England, Didcot, United Kingdom, ${ }^{7}$ Department of Molecular Biotechnology, Ghent \\ University, Ghent, Belgium
}

Background and Purpose: Radiotherapy is an essential tool for cancer treatment. In order to spare normal tissues and to reduce the risk of normal tissue complications, particle therapy is a method of choice. Although a large part of healthy tissues can be spared due to improved depth dose characteristics, little is known about the biological and molecular mechanisms altered after particle irradiation in healthy tissues. Elucidation of these effects is also required in the context of long term space flights, as particle radiation is the main contributor to the radiation effects observed in space. Endothelial cells (EC), forming the inner layer of all vascular structures, are especially sensitive to irradiation and, if damaged, contribute to radiation-induced cardiovascular disease.

Materials and Methods: Transcriptomics, proteomics and cytokine analyses were used to compare the response of ECs irradiated or not with a single 2 Gy dose of X-rays or Fe ions measured one and 7 days post-irradiation. To support the observed inflammatory effects, monocyte adhesion on ECs was also assessed.

Results: Experimental data indicate time- and radiation quality-dependent changes of the EC response to irradiation. The irradiation impact was more pronounced and longer lasting for Fe ions than for $\mathrm{X}$-rays. Both radiation qualities decreased the expression of genes involved in cell-cell adhesion and enhanced the expression of proteins involved in caveolar mediated endocytosis signaling. Endothelial inflammation and adhesiveness were increased with $\mathrm{X}$-rays, but decreased after Fe ion exposure.

Conclusions: $\mathrm{Fe}$ ions induce pro-atherosclerotic processes in ECs that are different in nature and kinetics than those induced by X-rays, highlighting radiation quality-dependent differences which can be linked to the induction and progression of 
cardiovascular diseases (CVD). Our findings give a better understanding of the underlying processes triggered by particle irradiation in ECs, a crucial aspect for the development of protective measures for cancer patients undergoing particle therapy and for astronauts in space.

Keywords: irradiation, radiotherapy, X-rays, Fe ions, linear energy transfer, endothelial cells, cardiovascular disease

\section{INTRODUCTION}

The main goal of radiotherapy is to efficiently target and eradicate tumors while sparing surrounding healthy tissues (Bentzen, 2006; Barnett et al., 2009). One of the recent developments in radiotherapy modalities is high linear energy transfer (LET) particle therapy (Stone et al., 2003). In this technique, accelerated charged particle beams, such as proton and carbon ions, are used (Wilson, 1946), which have improved depth dose characteristics in comparison to low LET radiotherapy (Durante and Loeffler, 2010). In this way, tumors can be irradiated with great precision, minimizing the dose to surrounding healthy tissues. Besides their physical advantage, charged particle beams induce more damage per unit of dose, i.e., demonstrate a higher relative biological effectiveness (RBE) compared to conventional low LET X-ray radiotherapy (Kramer et al., 2003; Schulz-Ertner and Tsujii, 2007). Despite this advantage, particle therapy is not commonly used due to its complex and expensive nature. Consequently, particle therapy currently focuses on localized tumors in proximity to critical organs and tumors resistant to conventional treatments, such as uveal melanoma, pediatric tumors, head-and-neck cancer and prostate cancer (SchulzErtner and Tsujii, 2007; Durante and Loeffler, 2010). In the last 10 years, however, there has been an exponential growth of new facilities (Jermann, 2015), a rapid increase in the number of patients treated (Jermann, 2015) and several new indications including lung cancer (Chang et al., 2016), breast cancer (Akamatsu et al., 2014), and pancreatic cancer (Nichols et al., 2015). Nonetheless, due to the limited number of patients treated with particle therapy at present, induction of normal tissue damage cannot be predicted correctly as molecular pathways and biological functions altered by high LET radiotherapy are still largely unknown (Schulz-Ertner and Tsujii, 2007; Durante and Loeffler, 2010; Newhauser and Durante, 2011). Identification and characterization of these processes is not only imperative for the development of protective measures for cancer patients undergoing high LET radiotherapy, but also for astronauts in space. Indeed, high LET particles are omnipresent in space as part of cosmic radiation. Among these particles, iron $(\mathrm{Fe})$ ions are the major contributor to biological radiation effects due to their high LET value (Moreels et al., 2012; Fernandez-Gonzalo et al., 2017).

One of the known consequences of conventional low LET radiotherapy is an increased risk of cardiovascular diseases (CVD), especially when the heart is located within the radiation field (Darby et al., 2013; Aleman et al., 2014). For example, low LET radiation exposure during breast cancer therapy has been shown to accelerate atherosclerosis leading to CVD (Darby et al., 2013). CVD is an umbrella term for several types of disorders that affect the heart, such as cardiomyopathy and heart failure, or blood vessels, such as coronary artery disease (Kumar et al., 2013). Although many aspects of the mechanisms by which ionizing radiation (IR) causes CVD are still unknown, evidence indicates that it acts at least in part by inducing endothelial cell (EC) dysfunction leading to increased oxidative stress, inflammation, coagulation, senescence and EC death (Vita and Keaney, 2002; Corre et al., 2013; Rombouts et al., 2013, 2014; Yentrapalli et al., 2013a,b; Widmer and Lerman, 2014; Azimzadeh et al., 2015; Baselet et al., 2017). These responses may eventually lead to the onset and/or progression of atherosclerosis, the leading cause of CVD (Schultz-Hector and Trott, 2007; Borghini et al., 2013). Compared to low LET, even less is known about the effects of high LET irradiation in the context of radiation-induced CVD. High LET irradiation was nevertheless found to be more damaging for ECs (Grabham et al., 2011; Helm et al., 2016) and to inhibit blood vessel formation differently than low LET irradiation (Grabham et al., 2013). Furthermore, atherogenesis was accelerated in obese apoE $\mathrm{E}^{-/-}$ mice at both 13 and 40 weeks after exposure to 2 and 5 Gy Fe ions (Yu et al., 2011). In rats, 1 Gy of Fe ions has been shown to relaxation, increased reactive oxygen species levels and decreased nitric oxide production, indicating endothelial dysfunction, which was associated with increased aortic stiffness and impaired endothelial-dependent (Soucy et al., 2011). Taking into account the increasing use of high LET radiation in cancer therapy (Jermann, 2015), there is an obvious necessity to further study its possible cardiovascular effects.

In this study, we hypothesized that high LET exposure would induce more EC dysfunction related processes in exposed ECs when compared to low LET exposure. Therefore, we aimed to compare the transcriptomic, proteomic and pro-inflammatory response of ECs irradiated with either $\mathrm{Fe}$ ions or X-rays. We identified differences in signaling pathways and response mechanisms influenced by low (X-ray) compared to high (Fe ion) LET radiation in telomerase-immortalized human coronary artery ECs. ECs were irradiated or not with a single dose of 2 Gy and changes were measured after 1 and 7 days. We conducted both transcriptomic and proteomic analyses, which were complemented with pro-inflammatory cytokine quantification and monocyte adhesion tests on irradiated ECs. We report time- and radiation qualitydependent changes in the EC response after exposure to IR. 


\section{MATERIALS AND METHODS}

\section{Cells, Reagents and Irradiation}

ECs from human coronary artery were purchased from European Cell Culture Collection (HCAECs Cat. No: 300-05) and transduced with retroviruses bearing the est 2 gene, a yeast homolog of the human TERT protein. ECs were grown in Human MesoEndo Endothelial Cell Medium (Cat. No. 212500 , Cell Applications) and cultured at $37^{\circ} \mathrm{C}$ with $5 \% \mathrm{CO}_{2}$ in a humidified incubator as described previously (Lowe and Raj, 2014). Cell were counted (Beckman Coulter counter) and seeding was carried out 2 days prior to irradiation with 40,000 cells $/ \mathrm{cm}^{2}$ in $0.4 \mathrm{ml} \mathrm{medium} / \mathrm{cm}^{2}$. This resulted in a confluence of $90-$ $100 \%$ at the time of irradiation visualized on a Leica DMI4000b microscope (Leica Microsystems). ECs were exposed to 2 Gy of X-ray irradiation using an AGO HS320/250 X-ray cabinet $(250 \mathrm{kV}, 13 \mathrm{~mA}, 1.5 \mathrm{~mm} \mathrm{Al}, 1.2 \mathrm{~mm} \mathrm{Cu}, 3 \mathrm{KeV} / \mu \mathrm{m})$ or Fe ions $(1 \mathrm{GeV} / \mathrm{u}, 155 \mathrm{keV} / \mu \mathrm{m})$, both with a dose rate of $1.5 \mathrm{~Gy} / \mathrm{min}$. Fe ion irradiation of EC monolayers was performed in the entrance channel of the beam to mimic the effects on healthy tissues. $1 \mathrm{GeV}$ $\mathrm{Fe}$ ions occurs in the plateau region of the depth dose profile and has a penetration depth of $25 \mathrm{~cm}$ in water (Scholz, 2003; Lee et al., 2011). Cells were not passaged during experiments to simulate normal, quiescent endothelium, but medium was changed regularly to ensure viability (three times per week after $\mathrm{X}$-ray and twice per week after Fe ion irradiation).

\section{Transcriptomic Analysis}

Microarray Preparation, Analysis, and Statistics

Total RNA of ECs was extracted according to manufacturer's instructions using the AllPrep DNA/RNA/protein mini kit (Qiagen). RNA was quantified using a NanoDrop Spectrophotometer and its quality assessed with an Agilent 2100 Bioanalyzer. Samples with a RNA integrity number $>8$ were used for hybridization onto Affymetrix Human Gene 2.0 ST arrays, following manufacturer's instructions. Raw data were uploaded to the Partek Genomics Suite (version 6.6) and normalized using a customized Robust Multi-chip Analysis algorithm (background correction for entire probe sequence, quantile normalization, $\log 2$ transformation of intensity signals). Microarray data were filtered to exclude genes expressed below the background signal in at least $67 \%$ of all samples and analyzed using three-way ANOVA. Differentially expressed genes were identified as those with a fold change $>|1.2|$ and $p<0.05$ after correction for multiple testing according to Benjamini and Hochberg (1995). The data have been deposited in the ArrayExpress database (http://www.ebi.ac.uk/arrayexpress; accession number E-MTAB-5754).

\section{Functional Enrichment Analysis}

Functional gene enrichment was performed and visualized using the GOrilla tool (Eden et al., 2007, 2009). Settings were: organism: Homo sapiens; running mode: two unranked lists of genes (target list: differentially expressed genes, background list: genes expressed above background in at least $33 \%$ of all samples); $p<0.001$. To exclude redundant gene ontology terms, results were reduced using REViGO (Rudjer Boskovic Institute, Croatia) with an allowed similarity of 0.4 (Supek et al., 2011). The version of Gene Ontology used was go_201507-termdb.oboxml.gz (http://archive.geneontology.org/full/2015-07-01/).

\section{Proteomic Analysis}

\section{Protein Labeling}

Protein labeling with isotope-coded protein labels (ICPL) was done as previously reported (Azimzadeh et al., 2013). Briefly, triplicate aliquots of $25 \mu \mathrm{g}$ of cell lysate proteins obtained from either sham or irradiated ECs were labeled with ICPL reagents (SERVA) following manufacturer's instructions. ICPL0 was used for sham-irradiated ECs and ICPL6 for irradiated cells. Labeling was done using three biological replicates per condition. Heavy and light labeled samples were combined and separated by $12 \%$ SDS gel electrophoresis before staining with colloidal Coomassie solution.

\section{Protein Analysis}

After staining, SDS-PAGE lanes were cut into 5 slices and subjected to in-gel digestion with trypsin (SERVA), as previously described (Merl et al., 2012). Digested peptides were separated by reversed phase liquid chromatography (LC), and mass spectrometry (MS) analyses were done with a linear quadrupole ion trap-Orbitrap (LTQ Orbitrap XL) mass spectrometer (ThermoFisher) equipped with a nano-ESI source (Hauck et al., 2010). This method allowed for sequential isolation of up to 10 most intense ions, depending on signal intensity, for fragmentation on the linear ion trap using collision-induced dissociation at a target value of 100,000 ions. High resolution MS scans in the Orbitrap and MS/MS scans in the linear ion trap were performed in parallel. Target peptides already selected for MS/MS were dynamically excluded for $30 \mathrm{~s}$. Acquired MS/MS spectra were searched against the Ensembl Human database using Mascot (Matrix Science, version 2.3.02; 20140909, Number of sequences: 100607) with the following parameters: MS/MS spectra were searched with a precursor mass tolerance of $10 \mathrm{ppm}$ and a fragment tolerance of $0.8 \mathrm{Da}$; Arg-C was selected as enzyme. One missed cleavage was allowed, and carbamidomethylation was set as a fixed modification. Oxidized methionine and the heavy and light ICPL labeled lysines as well as heavy and light labels of proteins were set as variable modifications.

\section{Protein Identification and Quantification}

Data processing for protein identification and quantification of ICPL pairs was performed using Proteome Discoverer version 1.3 (Thermo Fisher). This software provides automated strict statistical analysis of the protein quantification using unique peptides only. To minimize experimental bias, the software was set to normalize on the protein median (minimum protein count: 20). Complete peptide and protein profiles were filtered using high peptide confidence and top one peptide rank filters. False discovery rate (FDR) was calculated at the peptide level for all experimental runs using the Decoy option in Mascot; this rate was estimated to be lower than $1 \%$ using the identity threshold as the scoring threshold system. Differentially labeled isotopic pairs were detected with a mass precision of $2 \mathrm{ppm}$ and a retention time 
window of $0.3 \mathrm{~min}$. Proteins identified by at least two unique peptides in two out of three replicates, with ratios of heavy / light $(\mathrm{H} / \mathrm{L})$ label $>1.50$-fold or $<0.66$-fold ( $t$-test, $p<0.05$ ) were defined as significantly differentially expressed. Raw MS data have been deposited in the STORE ${ }^{\mathrm{DB}}$ database (http://www. storedb.org; dataset identifier doi: 10.20348/STOREDB/1086).

\section{Protein-Protein Interaction and Signaling Networks}

Analysis of possible protein-protein interactions and signaling networks was performed with the INGENUITY Pathway Analysis (IPA) software tool (INGENUITY System, http://www. INGENUITY.com). IPA is a knowledge database generated from peer-reviewed scientific publications that enables to discover highly represented functions and pathways $(p<0.001)$ from large quantitative data sets (Wu et al., 2007).

\section{Western Blotting}

For the validation of proteomics data, $10 \mu \mathrm{g}$ of cell protein extract was separated on $12 \%$ SDS polyacrylamide gels according to Laemmli (1970) before being transferred onto PVDF membranes and labeled with primary antibodies against caveolin-1 (\#3238, cell signaling) and $\alpha$-tubulin (\#GTX72291, GeneTex). Secondary antibodies were horseradish peroxidase-conjugated anti-rabbit and anti-mouse, respectively, and was detected usingthe ECL system (GE Healthcare). Signals were quantified using ImageJ software and normalized to the $\alpha$-tubulin expression.

\section{Functional Analyses \\ Cytokine Release Assays}

The release of interleukin (IL)-6, IL-8 and C-C motif chemokine ligand 2 (CCL2) was determined with enzymelinked immunosorbent assays (ELISAs; eBioscience). Cell culture supernatant was collected at the indicated time points after irradiation and frozen at $-80^{\circ} \mathrm{C}$. Medium was replaced $24 \mathrm{~h}$ before each time point to ensure cell viability and consistency. ELISAs were performed according to manufacturer's instructions. Measured cytokine concentrations were normalized to the cell number (Beckman Coulter counter), as total protein content per cell was dependent on irradiation dose, and the volume of supernatant at the time of collection, and calculated as fold change compared to control cells at matched time points.

\section{Monocyte Adhesion Assay}

Monocyte adhesion on ECs was tested as previously described (Lowe and Raj, 2014, 2015). In brief, ECs were seeded on fibronectin-coated glass coverslips and cultured until confluent. Seven days after irradiation, 500,000 Cell Tracker-labeled HL-60 monocytes (ThermoFisher Scientific) were added to the coverslip and incubated at $37^{\circ} \mathrm{C}$. After $30 \mathrm{~min}$, coverslips were washed with HBSS, fixed in formalin and embedded in Vectashield Hard Set mounting medium with 4'6-diamidino-2phenylindole (Vectorlabs H-1500). Monocytes adhering to ECs were microscopically quantified.

\section{Statistics}

The data show means \pm SEM. Differences between sham and irradiated samples at different time-points were determined by two-sided $t$-test (Welch-test). X-ray and Fe ion data are shown

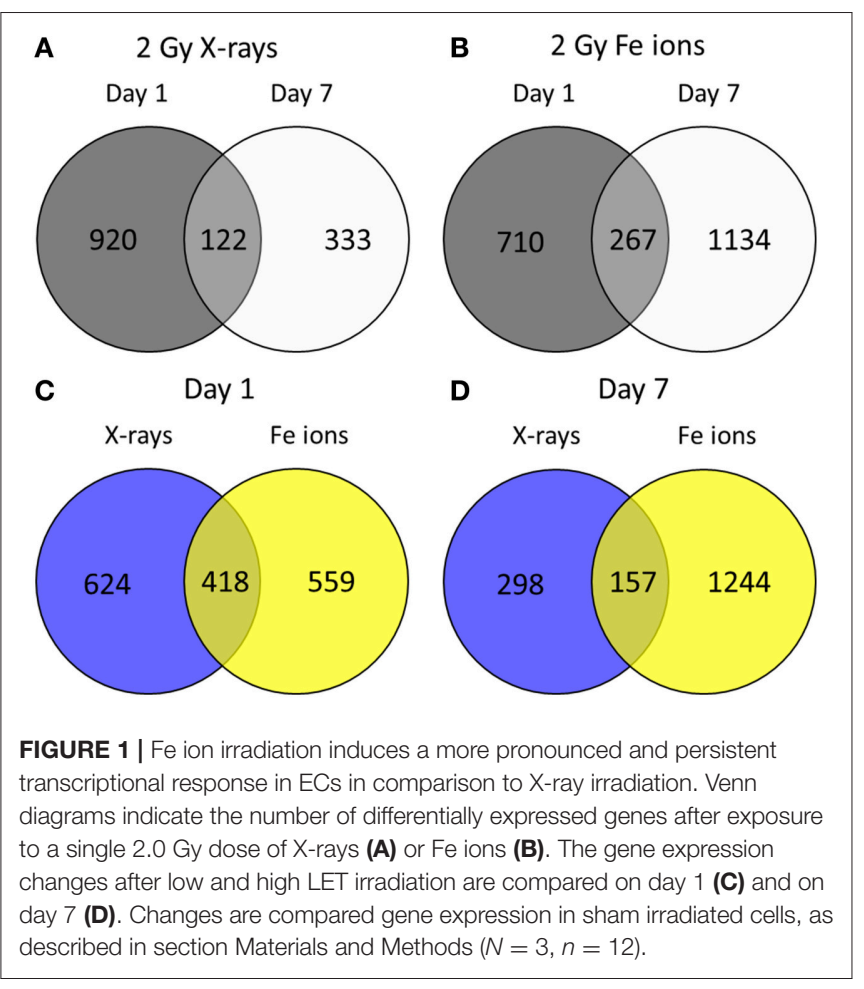

from three to one independent experiments, respectively. For Fe ion experiments, data represent 2 biological replicates with 2-3 technical replicates each. For X-ray experiments, data represent 9 biological replicates with 3 technical replicates each. $P<0.05$ was considered to be statistically significant.

\section{RESULTS}

\section{The Transcriptional Response of Fe Ion-Irradiated ECs Is More Pronounced and Persistent than the X-ray Radiation Response}

Little is known about the effects of high LET irradiation in the context of radiation-induced CVD. To gain more knowledge on the molecular pathways affected high LET irradiation, we tested whether irradiation of ECs with a single 2 Gy Fe ion dose induced different effects after 1 and 7 days in comparison to a single 2 Gy X-ray dose. Using a genome-wide gene expression analysis, we observed time- and radiation quality-dependent changes in gene expression. Differentially expressed genes (up or down-regulated) using Fe ion or X-ray irradiation are listed in Supplementary Data File 1. The number of deregulated genes and the shared deregulated genes between radiation qualities or time points are shown in Figure 1. A single X-ray dose of 2 Gy caused a profound effect on the gene expression on day 1 (1042 genes), which significantly decreased on day 7 (455 genes) (Figure 1A). Comparatively, Fe ions caused a smaller effect on gene expression at day 1 (977 genes), but this effect increased in size at day 7 (1401 genes) and demonstrated a 
TABLE 1 | X-ray irradiation of ECs induces an acute gene expression signature suggestive of cycle block and increased cellular adhesion. *

\begin{tabular}{|c|c|c|c|c|}
\hline & Upregulated description of process & $-\log 10(p$-value) & Downregulated description of process & $-\log 10$ (p-value) \\
\hline \multirow[t]{10}{*}{2 Gy X-rays Day 1} & Regulation of multicellular organismal process & 9 & Cell cycle process & 111 \\
\hline & Regulation of localization & 9 & Chromosome organization & 76 \\
\hline & Signal transduction & 9 & DNA metabolic process & 54 \\
\hline & Regulation of cellular component movement & 8 & Cell division & 50 \\
\hline & Regulation of locomotion & 8 & DNA replication & 44 \\
\hline & Cell adhesion & 7 & Cellular component organization or biogenesis & 36 \\
\hline & Biological adhesion & 7 & Chromosome segregation & 26 \\
\hline & Response to stimulus & 7 & Microtubule-based process & 19 \\
\hline & Regulation of cell proliferation & 7 & Regulation of chromosome segregation & 18 \\
\hline & Developmental process & 7 & DNA synthesis involved in DNA repair & 18 \\
\hline \multirow[t]{10}{*}{2 Gy X-rays Day 7} & Mitotic cell cycle process & 14 & Cell-substrate adhesion & 7 \\
\hline & Cell division & 10 & Extracellular matrix organization & 4 \\
\hline & Chromosome organization & 9 & Extracellular structure organization & 4 \\
\hline & DNA replication initiation & 9 & Ethanol oxidation & 4 \\
\hline & Cell proliferation & 6 & Biological adhesion & 4 \\
\hline & Chromosome segregation & 5 & Post-embryonic organ morphogenesis & 4 \\
\hline & Cellular component organization or biogenesis & 5 & Maintenance of location & 3 \\
\hline & Regulation of chromosome segregation & 5 & Maintenance of protein location in extracellular region & 3 \\
\hline & Negative regulation of blood coagulation & 4 & & \\
\hline & Response to hypoxia & 4 & & \\
\hline
\end{tabular}

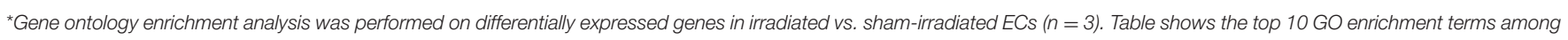
upregulated (left) and downregulated (right) differentially expressed genes at day 1 (top) and at day 7 after 2 Gy of X-rays (bottom).

larger overlap between both time points (Figure 1B). When comparing the samples irradiated with either X-rays or Fe ions, a lot of differentially expressed genes were shared at day 1 (418 genes), which was lost for the most part at day 7 (157 genes) (Figures 1C,D).

\section{Irradiation of ECs Represses the Expression of Genes Involved in Cell Cycling and Cell-Cell Adhesion}

Functional enrichment analysis revealed that, 1 day after exposure to a single X-ray dose of $2 \mathrm{~Gy}$, upregulated differentially expressed genes were involved in cell-cell adhesion, whereas downregulated differentially expressed genes in cell cyclerelated processes, such as DNA replication and chromosome segregation (Table 1, upper panel and Supplementary Data File 2). On day 7 after exposure to a single X-ray dose of 2 Gy, gene ontology analysis highlighted the acute nature of the induced transcriptional changes. Upregulated differentially expressed genes were involved in cell cycle-related processes (top 10 upregulated: CCNA1, UBE2S, CDC6, MAD2L1, QRC1, AURKA, MCM4, CKS2, SPAG5, and CDCA8; Figure 2), whereas downregulated differentially expressed genes played a role in cellcell adhesion (top 10 downregulated: VWF, SNED1, ITGA10, ICAM1, FAT4, LAMA2, PCDHB14, HAPLN3, FBLN5, and $B C A M$; Figure 3) (Table 1, lower panel). The transcriptional response to low LET irradiation was then compared to that of a same 2 Gy dose of high LET IR. On day 1, Fe ionexposed ECs upregulated the expression of genes involved in cell cycle arrest, such as genes related to p53 DNA damage signal transduction, which was associated to a downregulation of genes involved in cell cycle-related processes, such as DNA replication and chromosome segregation (Table 2, upper panel). Fe ions also upregulated the expression of genes controlling apoptosis at day 1 post-irradiation (top 10 upregulated: MIR21, YBX3, MDM2, MIR222, ACER2, TP53INP1, ZMAT3, BTG2, GDF5, and PHLDA3; Figure 4). Seven days after exposure to a single $2 \mathrm{~Gy}$ dose of Fe ions, ECs demonstrated a downregulation of gene expression involved in cell cycle-related processes, indicating a persistent cell cycle response (Table 2, lower panel). As opposed to day 1, downregulation of the expression of genes involved in cell death regulation and cell-cell adhesion was observed.

\section{Fe Ion-Irradiated ECs Have More Differentially Expressed Proteins in Comparison to X-Rays, Indicating a Pronounced and Persistent Radiation Response in Comparison}

To determine if the proteomic effects in ECs are dependent on radiation quality, proteins derived from ECs irradiated with either a single 2 Gy Fe ion dose or a single 2 Gy X-ray dose were studied at 1 and 7 days after radiation exposure using a global proteomics analysis. The list of differentially expressed proteins is displayed in Supplementary Data File 3. The numbers of deregulated proteins using the two radiation qualities and time points are shown in Figure 5. While there was virtually no change 


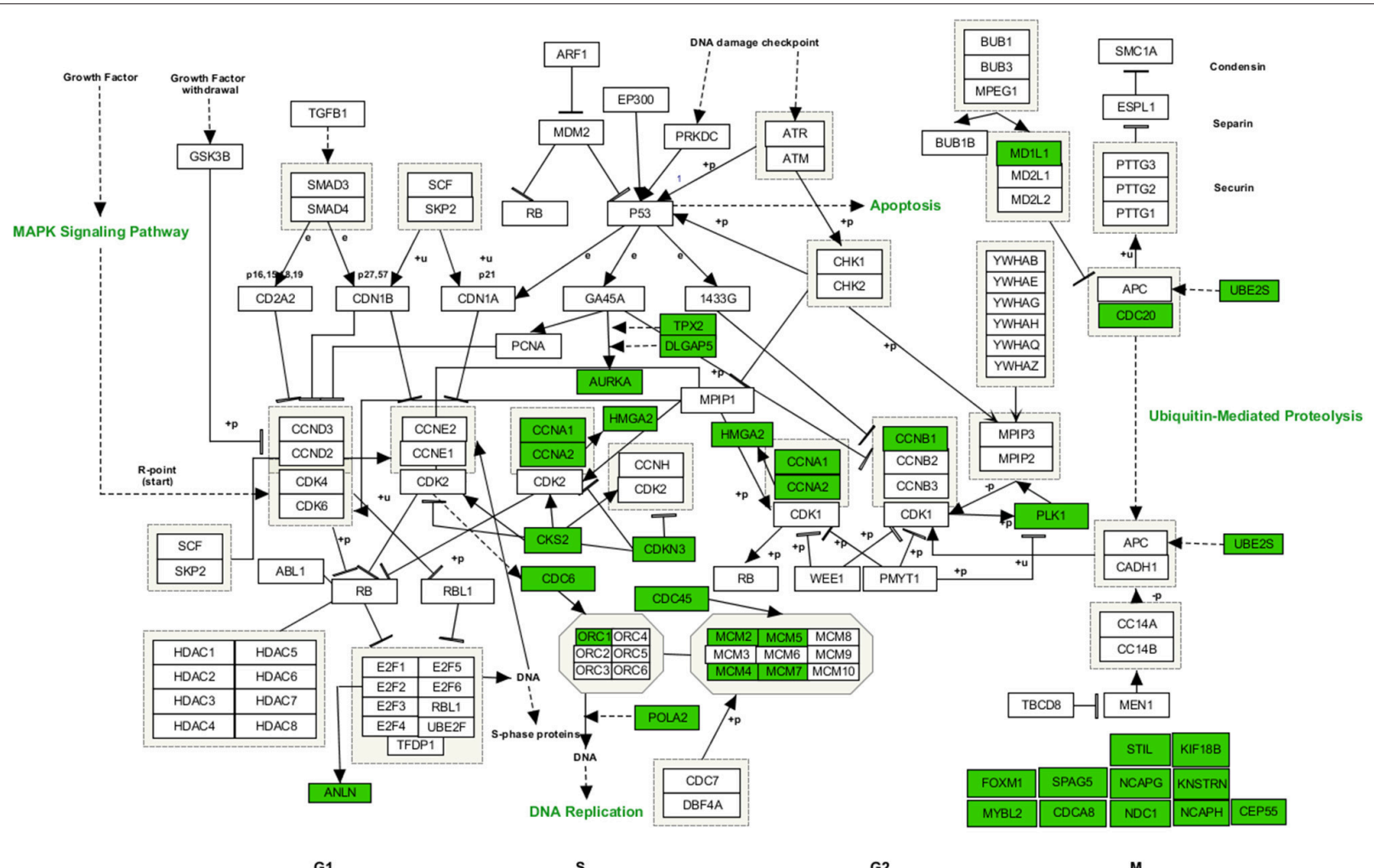

G1

G2

FIGURE 2 | Upregulated genes involved in cell cycle regulated processes at 7 days after a single dose of 2 Gy X-rays. Arborescence diagram indicates cell cycle pathway with the identified upregulated genes indicated in green. Pathway diagram was adapted from Wikipathways and modified with Pathvisio. Changes are shown compared to gene expression in sham irradiated cells $(N=3, n=12)$.

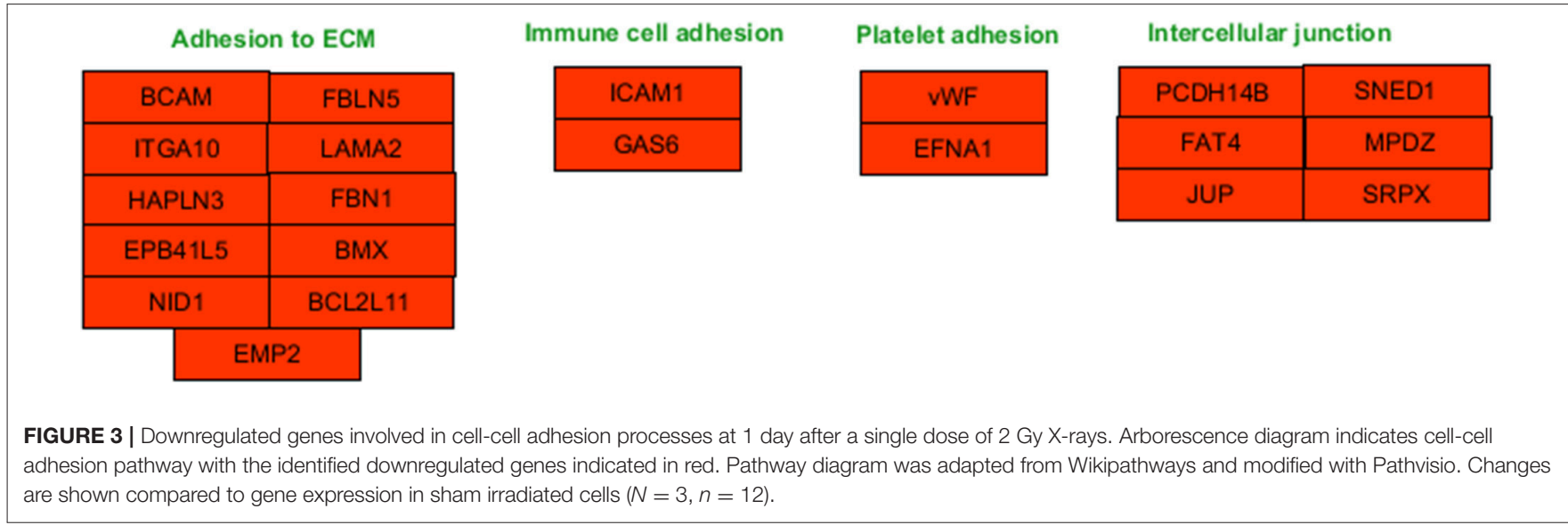

in the number of differentially expressed proteins (up and downregulated) between day 1 (70) and day 7 (74) after exposure to Xrays (Figure 5A), the number of differentially expressed proteins induced by Fe ion exposure almost doubled between day 1 and 7 (Figure 5B). In addition, compared to X-rays, Fe ions induced more differentially expressed proteins at day 1 (Figure 5C) and at day 7 post-irradiation (Figure 5D). The number of shared proteins between the two types of exposure was small, indicating a different protein fingerprint with the two radiation qualities in question.

\section{Although with Different Kinetics, Fe lons and X-Ray Irradiation Both Induce Protein Expression Involved in Caveolar Mediated Endocytosis Signaling and Cell-Cell Adhesion}

At 1 day after exposure to a single X-ray dose of 2 Gy, a detailed analysis of altered biological pathways revealed that differentially expressed proteins played a role in caveolar mediated endocytosis signaling (FLOT2, FLNC, PTPN1, and CAV1; Figure 6) and in 
TABLE 2 | Fe ion irradiation of ECs induces a gene expression signature suggesting persistent cell cycle block and decreased cellular adhesion. ${ }^{*}$

\begin{tabular}{|c|c|c|c|c|}
\hline & Upregulated description of process & $\begin{array}{l}-\log 10 \\
\text { (p-value) }\end{array}$ & Downregulated description of process & $-\log 10$ (p-value) \\
\hline \multirow[t]{10}{*}{2 Gy Fe ions Day 1} & Signal transduction by p53 class mediator & 11 & Cell cycle process & 99 \\
\hline & $\begin{array}{l}\text { DNA damage response, signal transduction by p53 class } \\
\text { mediator }\end{array}$ & 7 & Chromosome organization & 67 \\
\hline & Positive regulation of cell cycle arrest & 7 & Cell division & 49 \\
\hline & Response to radiation & 7 & DNA metabolic process & 49 \\
\hline & Signal transduction in response to DNA damage & 7 & DNA replication & 43 \\
\hline & Response to abiotic stimulus & 7 & Cellular component organization or biogenesis & 38 \\
\hline & Regulation of cell proliferation & 7 & Chromosome segregation & 26 \\
\hline & Regulation of apoptotic process & 6 & Microtubule-based process & 19 \\
\hline & Response to stimulus & 6 & Regulation of chromosome segregation & 18 \\
\hline & Chondroblast differentiation & 5 & Negative regulation of gene expression, epigenetic & 17 \\
\hline \multirow[t]{10}{*}{2 Gy Fe ions Day 7} & Developmental process & 8 & Regulation of endothelial cell migration & 10 \\
\hline & Negative regulation of response to stimulus & 8 & Negative regulation of nucleic acid-templated transcription & 10 \\
\hline & Regulation of locomotion & 7 & Regulation of signal transduction & 9 \\
\hline & Regulation of cell proliferation & 7 & Developmental process & 8 \\
\hline & Locomotion & 7 & Cytoskeleton organization & 7 \\
\hline & Single-organism process & 7 & Response to endogenous stimulus & 6 \\
\hline & Positive regulation of biological process & 7 & Regulation of cell death & 6 \\
\hline & Single-organism developmental process & 7 & Regulation of cell cycle & 6 \\
\hline & Regulation of multicellular organismal process & 7 & Regulation of cell proliferation & 6 \\
\hline & Regulation of protein metabolic process & 7 & Cell adhesion & 6 \\
\hline
\end{tabular}

*Gene ontology enrichment analysis (process) was performed on differentially expressed genes in irradiated vs. sham-irradiated ECs ( $n=3)$. Table shows the top $10 \mathrm{GO}$ enrichment terms among upregulated (left) and downregulated (right) differentially expressed genes on day 1 (top) or day 7 after 2 Gy of Fe ions (bottom).

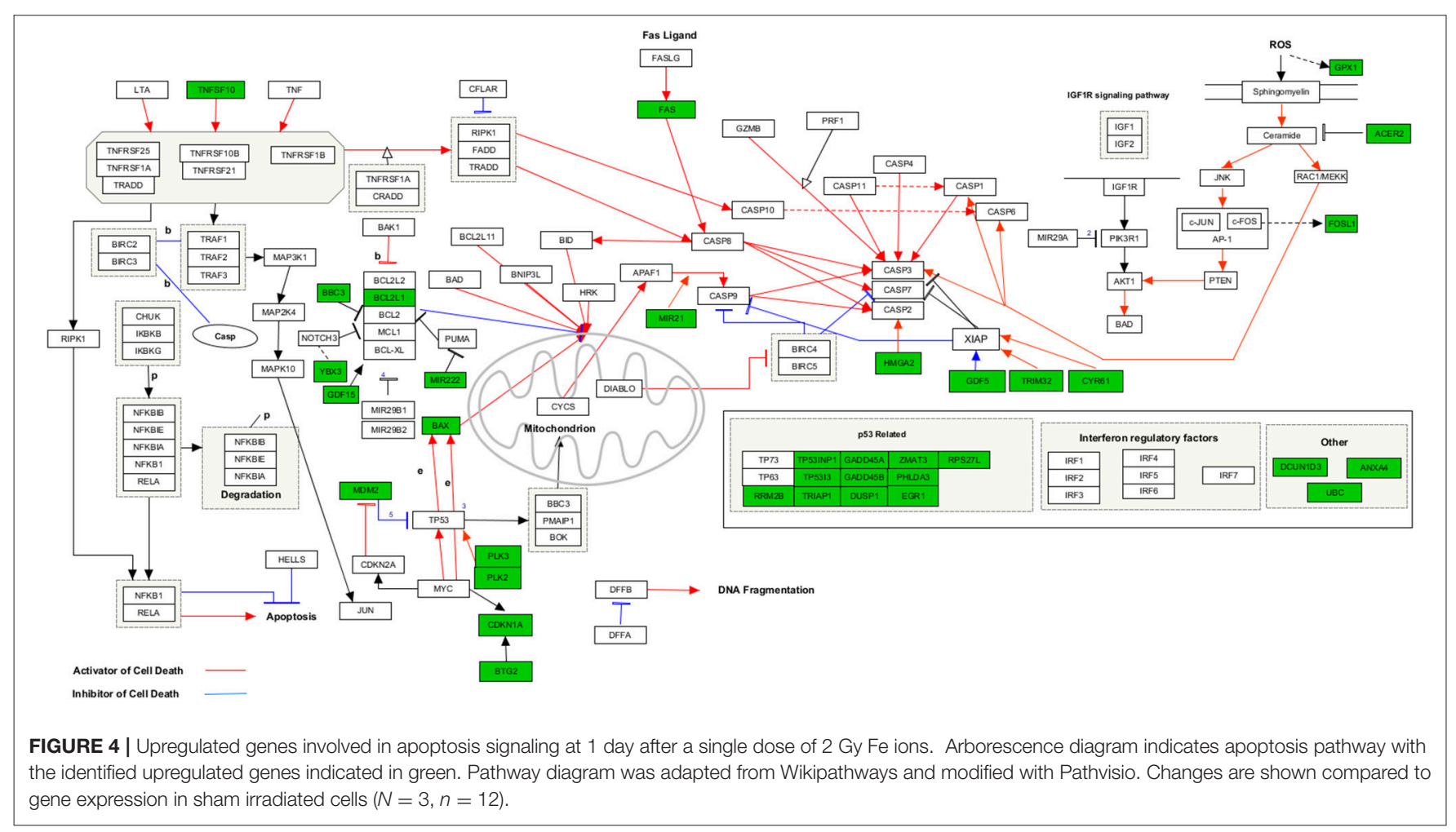




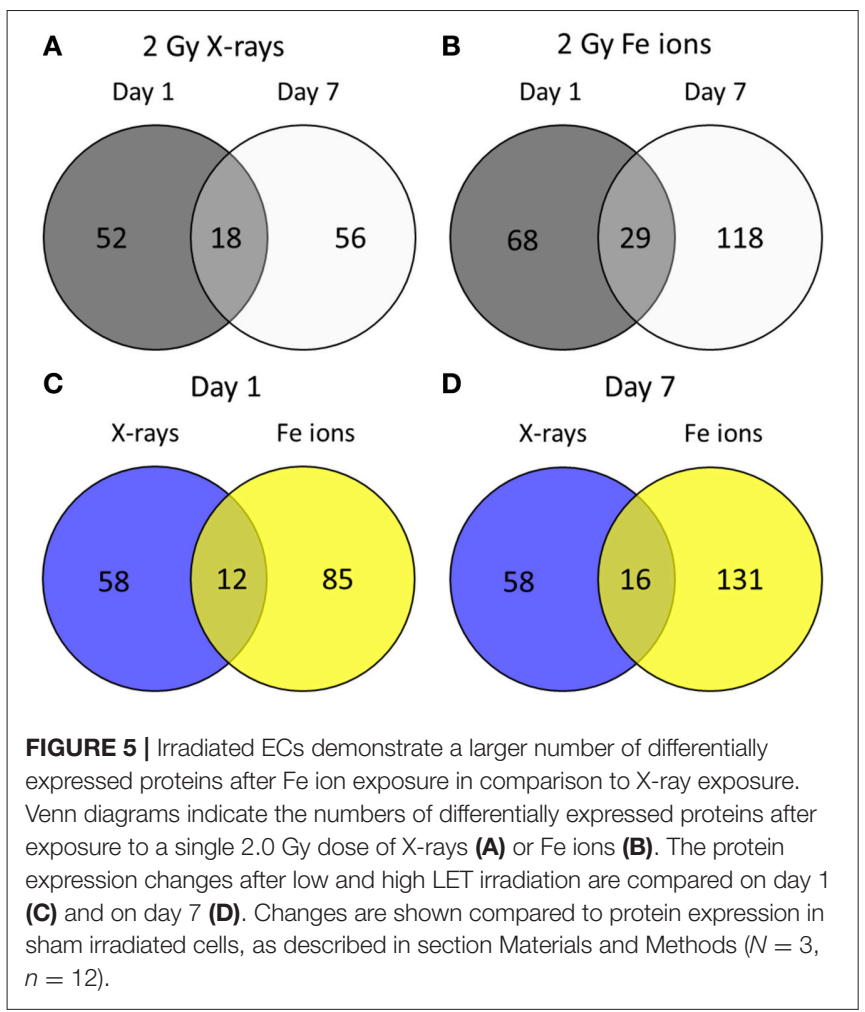

cell-cell adhesion, including integrin signaling (PFN1, ARF4, CAV1 and TLN1; Figure 6) and epithelial adherence junction signaling (CDH2 and CTNNB1; Figure 6) (Table 3, left panels and Supplementary Data File 4). Fe ion irradiation induced in general similar pathway changes, with differentially expressed proteins involved in endocytosis signaling and cell-cell adhesion, but at a later time point (day 7) (Table 3, right panels). While $\mathrm{X}$-rays markedly deregulated proteins involved in endocytosis signaling at both days, $\mathrm{Fe}$ ions only induced a marked effect at day 7 and merely a small but significant effect on day 1 . Furthermore, differentially expressed proteins involved in cell-cell adhesion were mostly observed at day 7 after $\mathrm{X}$-ray exposure, whereas they were mostly observed on day 1 following $\mathrm{Fe}$ ion exposure (Table 3, right panels). In addition to analysis of altered pathways, differentially expressed proteins were classified based on their molecular function (Table 4 and Supplementary Data File 5). Proteomic alterations covered a broad range of cellular events, including cell death and survival, cell cycle, cellular movement and cell-cell signaling. In light of the bidirectional regulation of proteins, all the shown pathways were derived from the entire proteomics data as no separation was performed between up- and downregulated proteins. To better document alteration of caveolar- mediated endocytosis signaling, we focused on caveolin-1, which is the main protein component of caveolae (Frank, 2010). EC exposure to X-rays induced a persistent downregulation of caveolin 1 expression detected suing western blotting day 1 and day 7 (Figures 7A,B). Comparatively, Fe ions only upregulated of caveolin 1 expression at day 7 after exposure, indicating a difference between both radiation types.

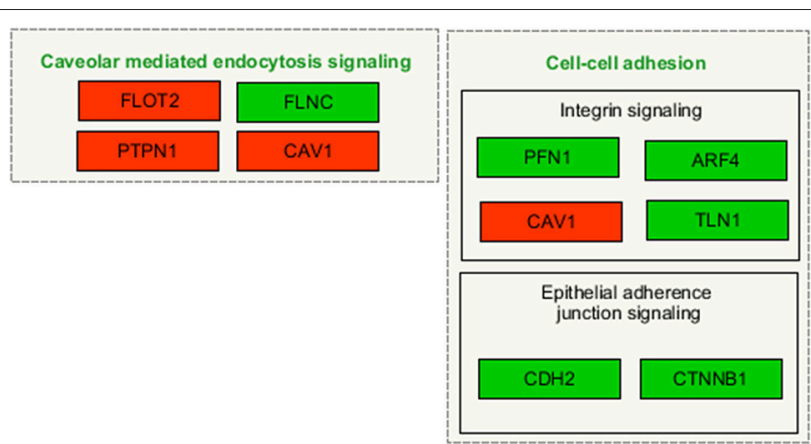

FIGURE 6 | Irradiated ECs differentially expressed proteins after X-ray exposure involved in caveolar-mediated endocytosis and cell-cell adhesion. Arborescence diagram indicates caveolar-mediated endocytosis signaling and cell-cell adhesion pathways with the identified upregulated genes indicated in green and downregulated genes in red. Pathway diagram was adapted from Wikipathways and modified with Pathvisio. Changes are shown compared to gene expression in sham irradiated cells $(N=3, n=12)$.

\section{X-Ray and Fe Ion Exposure Induces Cytokine Release and Alters Monocyte Adhesion}

In order to study the functional effect of irradiation on inflammatory processes in ECs, we focused on 3 proinflammatory cytokines known to be involved in atherosclerosis: IL-6 (Schuett et al., 2009), IL-8 (Boisvert et al., 1998), and CCL2 (Harrington, 2000). At $4 \mathrm{~h}$ after X-ray exposure and on day 1 after exposure to either $\mathrm{X}$-rays or $\mathrm{Fe}$ ions, there was no significant change in IL-6 and IL-8 levels measured using ELISA (Figures 8A-C). However, secreted CCL2 levels on day 1 increased only after exposure to X-rays. Seven days after exposure to a single dose of X-rays, ECs released more IL-6 (Figure 8B) and IL-8 (Figure 8C) but not CCL2 (Figure 8D) in comparison to control cells. In contrast, $\mathrm{Fe}$ ions did not significantly alter the secretion of IL-6 (Figure 8B) or IL-8 (Figure 8C), and CCL2 levels were below the detection threshold of ELISA assays (Figure 8D). When testing monocyte adhesion on ECs as a functional outcome of EC inflammation, X-rays were found to induce whilst Fe ions reduced monocyte adhesion on irradiated ECs 7 days post-irradiation (Figure 8E). Furthermore, irradiation with both $\mathrm{X}$-rays and $\mathrm{Fe}$ ions significantly reduced the number of ECs 7 days after exposure (Figure 8F).

\section{DISCUSSION}

Our study aimed at investigating differences in signaling pathways and radiation response mechanisms in ECs irradiated with a single $2 \mathrm{~Gy}$ dose of either $\mathrm{X}$-rays or Fe ions. We report time- and radiation type-dependent changes in the expression of genes and protein involved in cell cycle progression, cell-cell adhesion and caveolar-mediated endocytosis signaling. Furthermore, we found that X-ray irradiation induces EC release of pro-inflammatory cytokines IL-6 and IL-8 and increases monocyte adhesiveness of ECs, whilst Fe ions were found not to significantly induce cytokine secretion and reduced monocyte 
TABLE 3 | Fe ions and X-ray irradiation induces protein expression involved in caveolar mediated endocytosis signaling and cell-cell adhesion, but at different time points. *

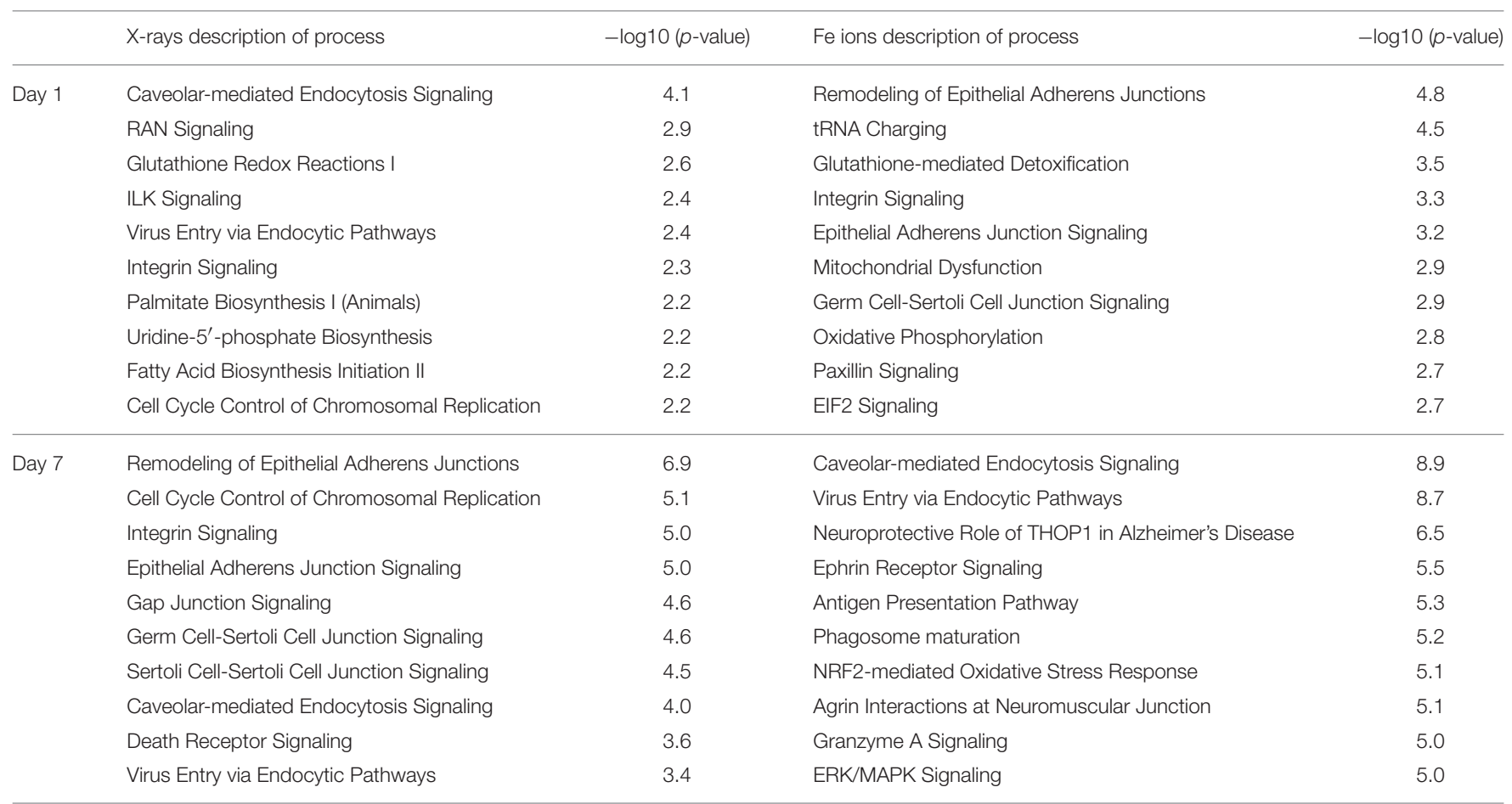

${ }^{*}$ Canonical pathway analysis was performed on differentially expressed proteins in irradiated vs. sham-irradiated ECs $(n=3)$. Table shows the top 10 molecular functions identified on day 1 (top) or day 7 (bottom) in ECs irradiated with 2 Gy of X-rays (left) or Fe ions (right).

TABLE 4 | Differently expressed proteins after Fe ion and X-ray irradiation are mainly involved in cell death, cell cycle and cell-cell signaling. *

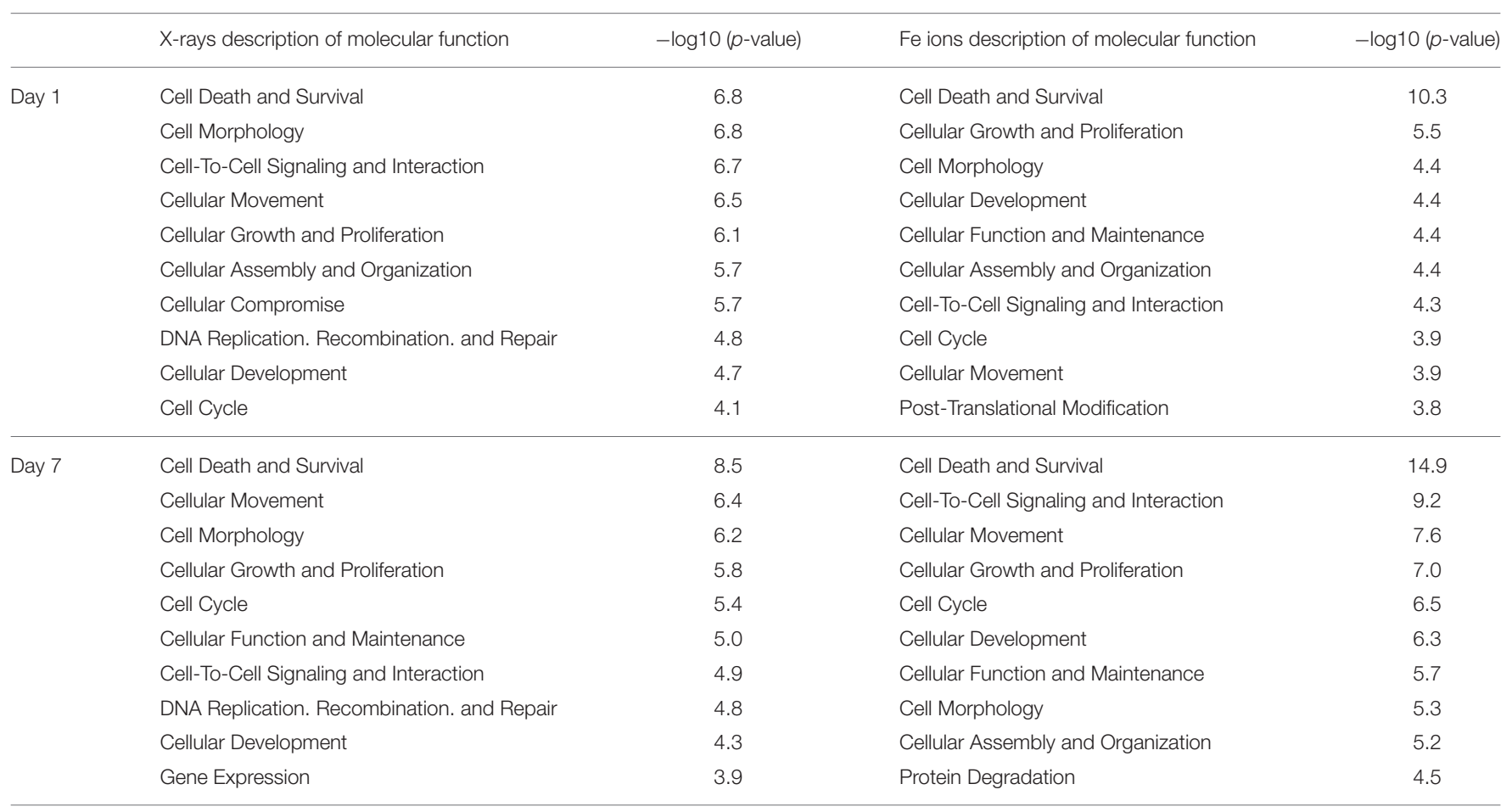

*Protein ontology analysis was performed on differentially expressed proteins in irradiated vs. sham-irradiated ECs $(n=3)$. Table shows the top 10 molecular functions identified on day 1 (top) or day 7 (bottom) in ECs after a 2 Gy irradiation with X-ray (left) or Fe ions (right). 


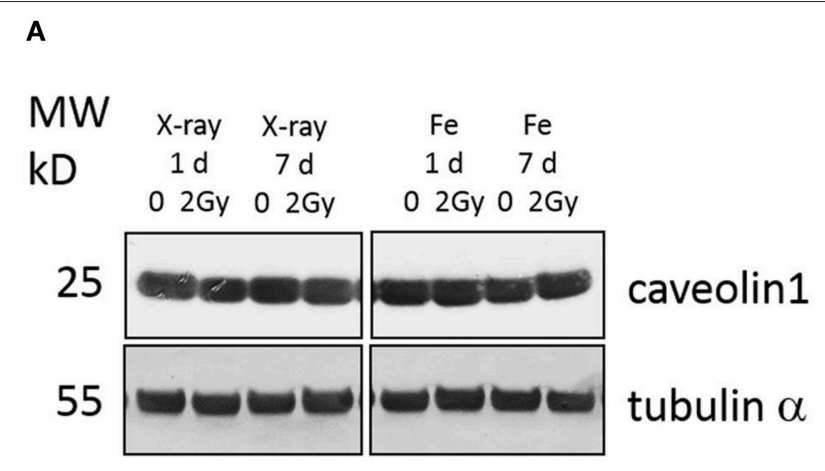

B control
$2 \mathrm{~Gy}$

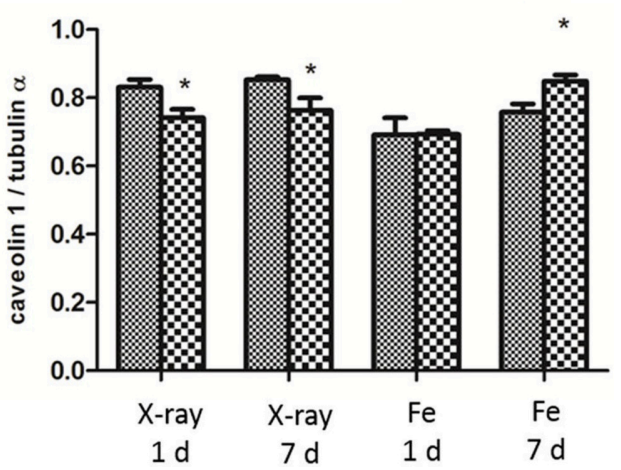

FIGURE 7 | X-ray irradiated ECs exhibit a persistent downregulation of caveolin-1, whereas Fe ion exposure induces a caveolin 1 upregulation. (A) Caveolin-1 (cav-1) and $\alpha$-tubulin protein expression analyzed using western blot after cell exposure to a single 2.0 Gy dose fo X-ray or Fe ions. (B) Data represent the cav-1/ $\alpha$-tubulin ratio in control and irradiated samples after background correction and normalization to $\alpha$-tubulin expression. Data show means $\pm \mathrm{SEM}(N=3, n=12) .{ }^{*} p \leq 0.05$ using two-sided $t$-test (Welch-test).

adhesiveness of ECs. These changes are indicative of a radiation quality-dependent changes in ECs, which can be linked to atherosclerosis and underscores the importance of conducting future research to better understand processes altered in healthy tissues exposed to high LET radiation.

It is generally accepted that high LET radiation (e.g., Fe ions) has a higher RBE in comparison to low LET radiation (e.g., X-rays) (ICRP, 2007). In accordance, we found that the transcriptional and proteomic impact of irradiation was more pronounced and longer lasting for $\mathrm{Fe}$ ions in comparison to $\mathrm{X}$-rays. At the gene expression level, both radiation qualities were shown to repress the expression of genes involved in cell cycling on day 1 , as previously demonstrated for $\mathrm{X}$-rays using the same in vitro model (Baselet et al., 2017). However, X-rayirradiated ECs induced the expression of cell-cycle genes on day 7 , indicating a reactivation of the cell cycle process (Baselet et al., 2017). In contrast, Fe ion irradiation persistently repressed the expression of genes associated with cell cycle regulation. A permanent cell cycle arrest after high LET exposure has also been demonstrated by others (Fournier and Taucher-Scholz, 2004; Suetens et al., 2016) and is believed to be a consequence of the complex, clustered hard-to-repair DNA damage it induces (Hada and Georgakilas, 2008; Asaithamby and Chen, 2011).

The observed changes of transcriptional and proteomic signaling involved in adhesion pathways in irradiated ECs may have two biological interpretations. Diminished EC adhesion signaling, as observed on day 7 after irradiation with both $\mathrm{X}$-rays and $\mathrm{Fe}$ ions, can be a result of angiogenic activation, a process initiating vascular extension from preexisting blood vessels and maintained by proliferating ECs (Folkman, 1971). Emerging evidence indicates that high LET inhibits (Takahashi et al., 2003; Mao et al., 2010; Grabham et al., 2013) and low LET radiation promotes angiogenesis (Sonveaux et al., 2003; Sofia Vala et al., 2010). However, angiogenic activation is less likely to have occurred after X-ray and Fe ion irradiation in our model because cell numbers were decreased. Cell number reduction in Fe iontreated samples was accompanied by decreased transcriptional and proteomic signaling linked to EC death and reduced proliferation, making angiogenic activation even less likely. A more likely explanation would be compromised EC integrity, corroborated by the observed decrease in EC number and adhesiveness in combination with signaling linked to increased EC death and reduced proliferation. In line with this, nickel ion radiation of ECs in vitro was found to induce the expression of genes involved in endothelial permeability and apoptosis (Beck et al., 2014). Furthermore, Fe ions induced a decreased EC number in vivo 12 months after exposure to a single 2 Gy dose (Mao et al., 2010). Loss of EC integrity may induce a number of adverse effects, including thrombus formation, and could predispose to the development of chronic pathologies, such as atherosclerosis leading to CVD (Widlansky et al., 2003; Deanfield et al., 2007; Munzel et al., 2008).

Another observation is the potential involvement of caveolar mediated endocytosis signaling in the EC response to IR exposure. Indeed, caveolin-1 (cav-1) protein expression was decreased on days 1 and 7 after X-ray exposure, whereas Fe ion exposure increased cav-1 expression on day 7 . During endocytosis, plasma membrane invagination leads to the formation of intracellular carrier vesicles that allow the engulfment of particles or fluids from the extracellular environment (de Duve, 1983). Although this process is known to occur during oxidative stress in ECs (Sundqvist and Liu, 1993; Liu and Sundqvist, 1995), less is known about caveolar mediated endocytosis during cellular responses to IR. The principal component protein of caveolae, caveolin-1 (Cav-1), has been shown to play a role in DNA damage repair (Zhu et al., 2010) and is therefore related to EC radiosensitivity (Klein et al., 2015). In addition, Caveolin 1 expression has been shown to suppress cell-cycle progression (Hulit et al., 2000) and inhibits angiogenesis (Liu et al., 1999; Morais et al., 2012) by mediating 


\section{A Cytokine release $4 \mathrm{~h}$ after $\mathrm{x}$-irradiation B}

Interleukin 6
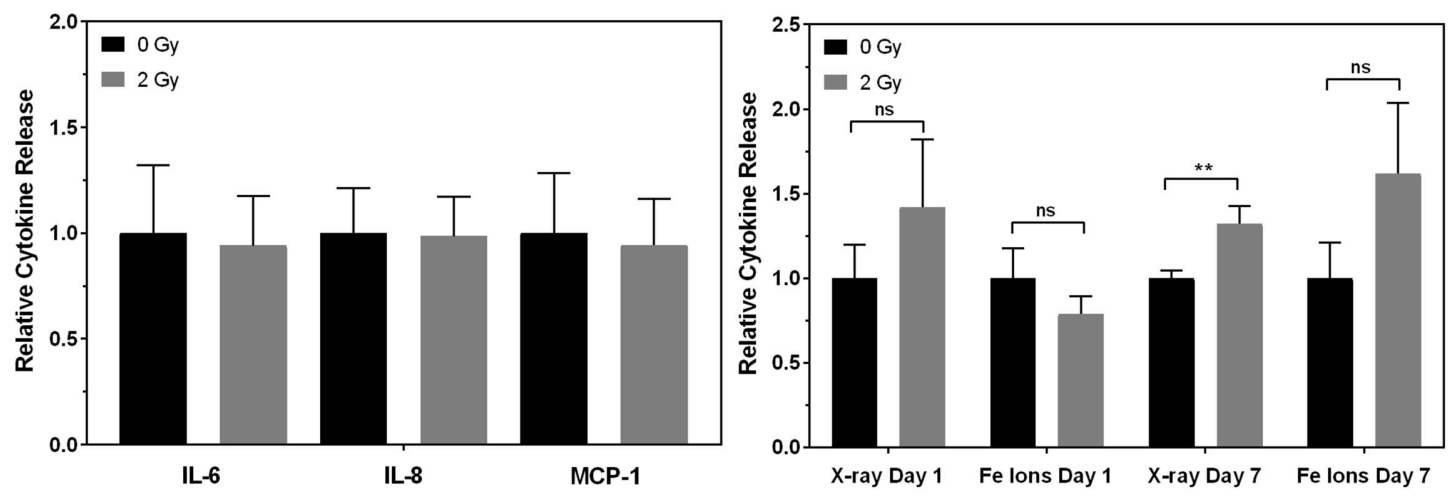

C

Interleukin 8

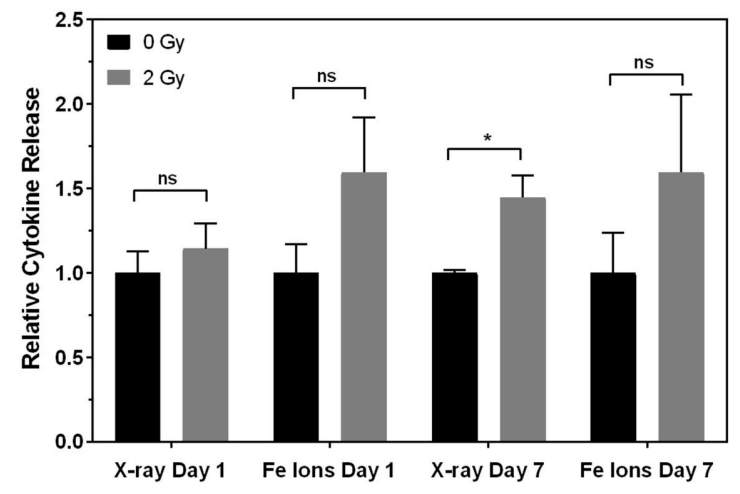

D

C-C motif chemokine ligand 2

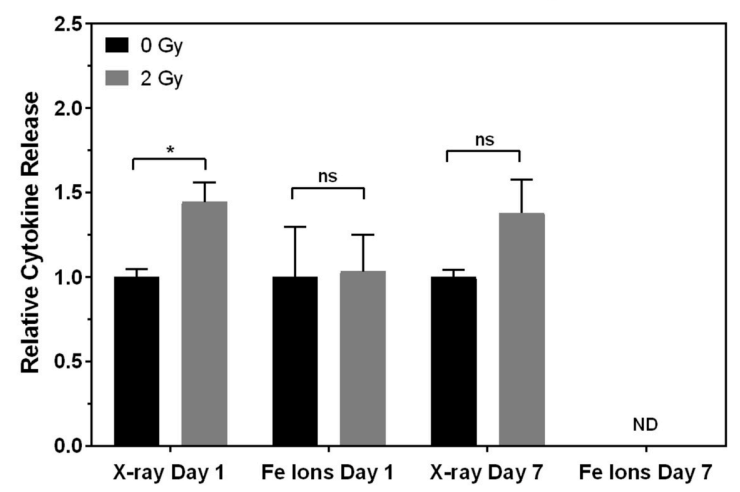

Cellnumbers

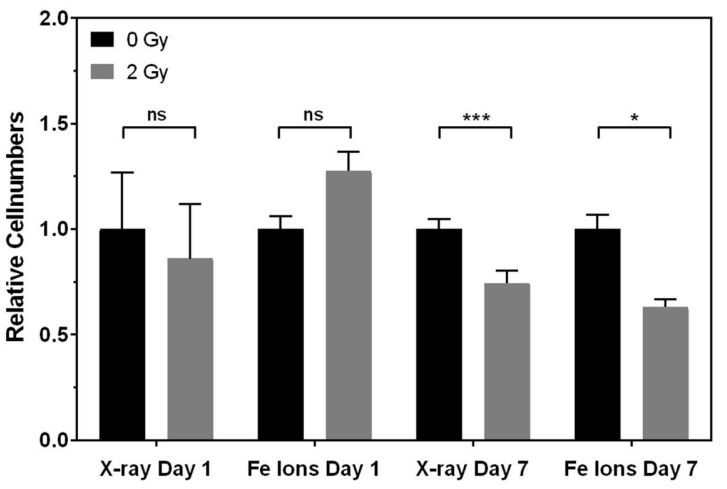

FIGURE 8 | X-ray irradiation causes EC inflammation and adhesiveness to monocytes, whilst Fe ion irradiation reduces cellular number and decreases EC adhesiveness to monocytes. The levels of IL-6, IL-8, and CCL2 secreted by EC on $4 \mathrm{~h}$ and day 1 plus day 7 (B-D) are shown after exposure to X-rays $(n=18-27)$ and Fe ions $(n=4-6)$. Data were normalized to cell numbers, supernatant volume, and control values. (E) The numbers of monocytes adhering to EC on day 7 are shown after exposure to X-rays $(n=90-225)$ and Fe ions $(n=30)$. Data was normalized to cell numbers and control values of sham-irradiated ECs. (F) EC numbers

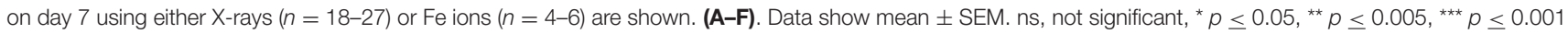
using two-sided $t$-test (Welch-test).

contact inhibition (Galbiati et al., 1998) and by reducing endothelial nitric oxide synthase abundance and activity (Sbaa et al., 2005). Consequently, an elevated endothelial expression of Cav-1 has been linked to processes underlying the development and progression of atherosclerosis (Fernandez-Hernando et al., 2010; Pavlides et al., 2014).
Inflammation plays a central role in the development, progression and final outcome of atherosclerosis (Libby, 2002). In this study, we evidenced that a single 2 Gy X-ray dose induces inflammation in ECs at day 7 after exposure, whereas 2 Gy Fe ions did not significantly induce inflammation. The proinflammatory effect of X-ray exposure was previously evidenced 
in the same in vitro model (Baselet et al., 2017). In accordance, others observed elevated IL-6 and IL-8 levels in 2-10 Gy X-ray-irradiated EC cultures (Meeren et al., 1997), elevated IL-6 levels in EC cultures after chronic irradiation with a total dose of 2 Gy (Ebrahimian et al., 2015) and elevated blood levels of IL-6 were detected in A-bomb survivors (Hayashi et al., 2003). These changes were previously demonstrated to increase EC adhesiveness to monocytes 1 day after exposure to X-ray doses higher than 5 Gy (Khaled et al., 2012). In contrast, reduced EC adhesiveness to monocytes in response to high LET IR is more controversial, since others have reported increased monocyte adherence to ECs 1 day after 2 and 5 Gy Fe ion exposure (Kucik et al., 2010; Khaled, 2011). In these studies, ECs were pretreated with tumor necrosis factor $\alpha$, known to induce EC adhesiveness to monocytes (Ikuta et al., 1991; Mackay et al., 1993), which may have caused a bias. Nonetheless, these authors used a flow chamber system that provides an environment with fluid shear stress resembling the in vivo blood vessel environment. In contrast to our findings, high LET radiation exposure has been shown to increase the in vitro expression of adhesion molecules (Kiyohara et al., 2011), which can lead to accelerated development and progression of atherosclerosis in obese apoE $\mathrm{E}^{-/-}$mice (Yu et al., 2011). These conflicting results highlight the need for further research with a particular focus on radiation dose and timing after exposure to univocally determine the effects of high LET radiation on EC inflammation in the frame of CVD.

In this study, we determined the effects of radiation quality on human coronary artery ECs seeing their importance in radiationinduced CVD (Vita and Keaney, 2002; Darby et al., 2013; Widmer and Lerman, 2014). As the Fe ions in this study were accelerated to $1 \mathrm{GeV}$ and had a penetration depth of up to $25 \mathrm{~cm}$ in water (Scholz, 2003; Lee et al., 2011), they are able to reach endothelial linings in the human body since tissue is generally considered to be similar to water. Although immortalized, these cells retain a normal EC phenotype, including genome stability (unpublished data), normal cell cycle regulation (Baselet et al., 2017), responsiveness to IR (Lowe and Raj, 2014) and the expression of all major EC phenotypic markers (e.g., von Willebrand factor and cadherin-5; unpublished data). Due to the large phenotypic heterogeneity between ECs derived from different vascular beds, care should be taken before generalizing our findings (Aird, 2007a,b). Furthermore, our in vitro model is not adapted to provide the entire complexity of the development of radiation-induced CVD in humans. Although Fe ions are a form of high LET radiation that is more relevant for the space environment than medical practice, they can provide valuable insights into the endothelial response to high LET exposure.

In conclusion, we found a time- and radiation quality dependent endothelial radiation response. In general, the radiation impact was more pronounced and longer lasting for Fe ions than for X-rays. Observed transcriptional and proteomic changes were involved in cell cycle regulation, cell death, caveolar mediated endocytosis signaling and EC permeability. In contrast to $\mathrm{Fe}$ ions, X-rays were found to induce EC inflammation and adhesiveness to monocytes. Besides the link with CVD development and progression, these findings are indicative of a different molecular response induced by the two types of irradiation. In the context of the ProCardio FP7 project, our findings will be integrated with other in vitro, in vivo and epidemiological data to increase our understanding of radiationinduced CVD. Although studies on the effect of high LET particles are scarce due to limited access to the radiation facilities, future research should continue aiming at elucidating the underlying molecular mechanisms induced by high LET radiation in ECs. Before exploring details of each modified pathway, our findings should be confirmed with independent irradiated EC samples. Besides the quality effect, emphasis should also be placed on the dose effect, as low and high dose irradiation may have different outcomes. Furthermore, radiation doses of $\mathrm{Fe}$ ions and $\mathrm{X}$-rays should be identified with an equal $\mathrm{RBE}$ in order to compare cellular responses to the 2 radiation types on the same scale of biological damage. A better understanding of the radiation-induced CVD risk is necessary for the protection of radiotherapy patients but also astronauts in space.

\section{AUTHOR CONTRIBUTIONS}

BB performed microarray analysis (functional enrichment analysis). Microarrays were performed by AJ and AM. OA and MVB performed the proteomic analysis. NE, TD, and SK quantified cytokines and endothelial adhesiveness. DL and KR created and validated the human coronary artery EC line. All authors helped with data interpretation, scientific guidance and preparation of the manuscript.

\section{FUNDING}

This work was funded by EU FP7 project ProCardio (grant \#295823), the Belgian Federal Agency for Nuclear Control FANC-AFCN (grant \#CO-90-13-3289-00) and the Belgian Fonds National de la Recherche Scientifique (F.R.S.-FNRS). BB is supported by a doctoral SCK•CEN/Université catholique de Louvain grant. PS is a F.R.S.-FNRS Senior Research Associate. Funding sources had no role in study design, data collection analysis and interpretation, the writing and submission of the manuscript for publication.

\section{ACKNOWLEDGMENTS}

Authors thank Stefanie Winkler for skillful technical assistance.

\section{SUPPLEMENTARY MATERIAL}

The Supplementary Material for this article can be found online at: http://journal.frontiersin.org/article/10.3389/fphar. 2017.00570/full\#supplementary-material 


\section{REFERENCES}

Aird, W. C. (2007a). Phenotypic heterogeneity of the endothelium: I. structure, function, and mechanisms. Circ. Res. 100, 158-173. doi: 10.1161/01.RES.0000255691.76142.4a

Aird, W. C. (2007b). Phenotypic heterogeneity of the endothelium: II. representative vascular beds. Circ. Res. 100, 174-190. doi: 10.1161/01.RES.0000255690.03436.ae

Akamatsu, H., Karasawa, K., Omatsu, T., Isobe, Y., Ogata, R., and Koba, Y. (2014). First experience of carbon-ion radiotherapy for early breast cancer. Jpn. J. Radiol. 32, 288-295. doi: 10.1007/s11604-014-0300-6

Aleman, B. M., Moser, E. C., Nuver, J., Suter, T. M., Maraldo, M. V., Specht, L., et al. (2014). Cardiovascular disease after cancer therapy. EJC Suppl. 12, 18-28. doi: 10.1016/j.ejcsup.2014.03.002

Asaithamby, A., and Chen, D. J. (2011). Mechanism of cluster DNA damage repair in response to high-atomic number and energy particles radiation. Mutat. Res. 711, 87-99. doi: 10.1016/j.mrfmmm.2010.11.002

Azimzadeh, O., Sievert, W., Sarioglu, H., Merl-Pham, J., Yentrapalli, R., Bakshi, M. $\mathrm{V}$., et al. (2015). Integrative proteomics and targeted transcriptomics analyses in cardiac endothelial cells unravel mechanisms of long-term radiation-induced vascular dysfunction. J. Proteome Res. 14, 1203-1219. doi: 10.1021/pr501141b

Azimzadeh, O., Sievert, W., Sarioglu, H., Yentrapalli, R., Barjaktarovic, Z., Sriharshan, A., et al. (2013). PPAR alpha: a novel radiation target in locally exposed mus musculus heart revealed by quantitative proteomics. J. Proteome Res. 12, 2700-2714. doi: 10.1021/pr400071g

Barnett, G. C., West, C. M., Dunning, A. M., Elliott, R. M., Coles, C. E., Pharoah, P. D., et al. (2009). Normal tissue reactions to radiotherapy: towards tailoring treatment dose by genotype. Nat. Rev. Cancer 9, 134-142. doi: 10.1038/nrc2587

Baselet, B., Belmans, N., Coninx, E., Lowe, D., Janssen, A., Michaux, A., et al. (2017). Functional gene analysis reveals cell cycle changes and inflammation in endothelial cells irradiated with a single X-ray dose. Front. Pharmacol. 8:213. doi: 10.3389/fphar.2017.00213

Beck, M., Rombouts, C., Moreels, M., Aerts, A., Quintens, R., Tabury, K., et al. (2014). Modulation of gene expression in endothelial cells in response to high LET nickel ion irradiation. Int. J. Mol. Med. 34, 1124-1132. doi: 10.3892/ijmm.2014.1893

Benjamini, Y., and Hochberg, Y. (1995). Controlling the false discovery rate a practical and powerful approach to multiple testing. J. R. Stat. Soc. Ser. B Methodol. 57, 289-300.

Bentzen, S. M. (2006). Preventing or reducing late side effects of radiation therapy: radiobiology meets molecular pathology. Nat. Rev. Cancer 6, 702-713. doi: $10.1038 / \mathrm{nrc} 1950$

Boisvert, W. A., Santiago, R., Curtiss, L. K., and Terkeltaub, R. A. (1998). A leukocyte homologue of the IL-8 receptor CXCR-2 mediates the accumulation of macrophages in atherosclerotic lesions of LDL receptor-deficient mice. J. Clin. Invest. 101, 353-363. doi: 10.1172/JCI1195

Borghini, A., Gianicolo, E. A., Picano, E., and Andreassi, M. G. (2013). Ionizing radiation and atherosclerosis: current knowledge and future challenges. Atherosclerosis 230, 40-47. doi: 10.1016/j.atherosclerosis.2013.06.010

Chang, J. Y., Jabbour, S. K., De Ruysscher, D., Schild, S. E., Simone, C. B. II., Rengan, R., et al. (2016). Consensus statement on proton therapy in early-stage and locally advanced non-small cell lung cancer. Int. J. Radiat. Oncol. Biol. Phys. 95, 505-516. doi: 10.1016/j.ijrobp.2016.01.036

Corre, I., Guillonneau, M., and Paris, F. (2013). Membrane signaling induced by high doses of ionizing radiation in the endothelial compartment. Relevance in radiation toxicity. Int. J. Mol. Sci. 14, 22678-22696. doi: 10.3390/ijms141122678

Darby, S. C., Ewertz, M., McGale, P., Bennet, A. M., Blom-Goldman, U., Bronnum, D., et al. (2013). Risk of ischemic heart disease in women after radiotherapy for breast cancer. N. Engl. J. Med. 368, 987-998. doi: 10.1056/NEJMoa12 09825

Deanfield, J. E., Halcox, J. P., and Rabelink, T. J. (2007). Endothelial function and dysfunction: testing and clinical relevance. Circulation 115, 1285-1295. doi: 10.1161/CIRCULATIONAHA.106.652859.

de Duve, C. (1983). Lysosomes revisited. Eur. J. Biochem. 137, 391-397. doi: 10.1111/j.1432-1033.1983.tb07841.x

Durante, M., and Loeffler, J. S. (2010). Charged particles in radiation oncology. Nat. Rev. Clin. Oncol. 7, 37-43. doi: 10.1038/nrclinonc.2009.183
Ebrahimian, T., Le Gallic, C., Stefani, J., Dublineau, I., Yentrapalli, R., HarmsRingdahl, M., et al. (2015). Chronic gamma-irradiation induces a doserate-dependent pro-inflammatory response and associated loss of function in human umbilical vein endothelial cells. Radiat. Res. 183, 447-454. doi: $10.1667 / R R 13732.1$

Eden, E., Lipson, D., Yogev, S., and Yakhini, Z. (2007). Discovering motifs in ranked lists of DNA sequences. PLoS Comput. Biol. 3:e39. doi: 10.1371/journal.pcbi.0030039

Eden, E., Navon, R., Steinfeld, I., Lipson, D., and Yakhini, Z. (2009). GOrilla: a tool for discovery and visualization of enriched GO terms in ranked gene lists. BMC Bioinformatics 10:48. doi: 10.1186/1471-2105-10-48

Fernandez-Gonzalo, R., Baatout, S., and Moreels, M. (2017). Impact of particle irradiation on the immune system: from the clinic to mars. Front. Immunol. 8:177. doi: 10.3389/fimmu.2017.00177

Fernandez-Hernando, C., Yu, J., Davalos, A., Prendergast, J., and Sessa, W. C. (2010). Endothelial-specific overexpression of caveolin-1 accelerates atherosclerosis in apolipoprotein E-deficient mice. Am. J. Pathol. 177, 998-1003. doi: 10.2353/ajpath.2010.091287

Folkman, J. (1971). Tumor angiogenesis: therapeutic implications. N. Engl. J. Med. 285, 1182-1186. doi: 10.1056/NEJM197111182852108

Fournier, C., and Taucher-Scholz, G. (2004). Radiation induced cell cycle arrest: an overview of specific effects following high-LET exposure. Radiother. Oncol. 73(Suppl. 2), S119-S122. doi: 10.1016/S0167-8140(04)80031-8

Frank, P. G. (2010). Endothelial caveolae and caveolin-1 as key regulators of atherosclerosis. Am. J. Pathol. 177, 544-546. doi: 10.2353/ajpath.2010.100247

Galbiati, F., Volonte, D., Engelman, J. A., Watanabe, G., Burk, R., Pestell, R. G., et al. (1998). Targeted downregulation of caveolin-1 is sufficient to drive cell transformation and hyperactivate the p42/44 MAP kinase cascade. EMBO J. 17, 6633-6648. doi: 10.1093/emboj/17.22.6633

Grabham, P., Hu, B., Sharma, P., and Geard, C. (2011). Effects of ionizing radiation on three-dimensional human vessel models: differential effects according to radiation quality and cellular development. Radiat. Res. 175, 21-28. doi: 10.1667/RR2289.1

Grabham, P., Sharma, P., Bigelow, A., and Geard, C. (2013). Two distinct types of the inhibition of vasculogenesis by different species of charged particles. Vasc. Cell 5:16. doi: 10.1186/2045-824X-5-16

Hada, M., and Georgakilas, A. G. (2008). Formation of clustered DNA damage after high-LET irradiation: a review. J. Radiat. Res. 49, 203-210. doi: $10.1269 /$ jrr.07123

Harrington, J. R. (2000). The role of MCP-1 in atherosclerosis. Stem Cells 18, 65-66. doi: 10.1634/stemcells.18-1-65

Hauck, S. M., Dietter, J., Kramer, R. L., Hofmaier, F., Zipplies, J. K., Amann, B., et al. (2010). Deciphering membrane-associated molecular processes in target tissue of autoimmune uveitis by label-free quantitative mass spectrometry. Mol. Cell Proteomics 9, 2292-2305. doi: 10.1074/mcp.M110.001073

Hayashi, T., Kusunoki, Y., Hakoda, M., Morishita, Y., Kubo, Y., Maki, M., et al. (2003). Radiation dose-dependent increases in inflammatory response markers in A-bomb survivors. Int. J. Radiat. Biol. 79, 129-136. doi: 10.1080/0955300021000038662

Helm, A., Lee, R., Durante, M., and Ritter, S. (2016). The Influence of C-ions and X-rays on human umbilical vein endothelial cells. Front. Oncol. 6:5. doi: 10.3389/fonc.2016.00005

Hulit, J., Bash, T., Fu, M., Galbiati, F., Albanese, C., Sage, D. R., et al. (2000). The cyclin D1 gene is transcriptionally repressed by caveolin-1. J. Biol. Chem. 275, 21203-21209. doi: 10.1074/jbc.M000321200

ICRP (2007). The 2007 Recommendations of the International Commission on Radiological Protection. ICRP publication 103. Ann. ICRP 37, 1-332. doi: 10.1016/j.icrp.2007.10.003

Ikuta, S., Kirby, J. A., Shenton, B. K., Givan, A. L., and Lennard, T. W. (1991). Human endothelial cells: effect of TNF-alpha on peripheral blood mononuclear cell adhesion. Immunology 73, 71-76.

Jermann, M. (2015). Particle Therapy Statistics in 2014. Int. J. Particle Ther. 2, 50-54. doi: 10.14338/IJPT-15-00013

Khaled, S. (2011). Low and high LET Irradiation of Human Aortic Endothelial Cells Induces Dose and Time Dependent Adhesion of Monocytes Which Is Mediated by Chemokines Expressed by the Irradiated Endothelium. Doctor of Philosophy, The University of Alabama. 
Khaled, S., Gupta, K. B., and Kucik, D. F. (2012). Ionizing radiation increases adhesiveness of human aortic endothelial cells via a chemokine-dependent mechanism. Radiat. Res. 177, 594-601. doi: 10.1667/RR2557.1

Kiyohara, H., Ishizaki, Y., Suzuki, Y., Katoh, H., Hamada, N., Ohno, T., et al. (2011). Radiation-induced ICAM-1 expression via TGF-betal pathway on human umbilical vein endothelial cells; comparison between X-ray and carbonion beam irradiation. J. Radiat. Res. 52, 287-292. doi: 10.1269/jrr.10061

Klein, D., Schmitz, T., Verhelst, V., Panic, A., Schenck, M., Reis, H., et al. (2015). Endothelial Caveolin-1 regulates the radiation response of epithelial prostate tumors. Oncogenesis 4:e148. doi: 10.1038/oncsis.2015.9

Kramer, M., Weyrather, W. K., and Scholz, M. (2003). The increased biological effectiveness of heavy charged particles: from radiobiology to treatment planning. Technol. Cancer Res. Treat. 2, 427-436. doi: $10.1177 / 153303460300200507$

Kucik, D. F., Khaled, S., Gupta, K., Wu, X., Yu, T., and Chang, P. Y. (2010). X-ray, proton and iron ion irradiation all increase adhesiveness of aortic endothelium and may accelerate development of atherosclerosis. FASEB J. 24(1 Suppl.), (1028).1011.

Kumar, V., Abbas, A. K., Aster, J. C., and Robbins, S. L. (2013). Robbins Basic Pathology. Philadelphia, PA: Elsevier/Saunders.

Laemmli, U. K. (1970). Cleavage of structural proteins during the assembly of the head of bacteriophage T4. Nature 227, 680-685. doi: 10.1038/227680a0

Lee, R., Nasonova, E., Hartel, C., Durante, M., and Ritter, S. (2011). Chromosome aberration measurements in mitotic and G2-PCC lymphocytes at the standard sampling time of $48 \mathrm{~h}$ underestimate the effectiveness of high-LET particles. Radiat. Environ. Biophys. 50, 371-381. doi: 10.1007/s00411-0110360-2

Libby, P. (2002). Inflammation in atherosclerosis. Nature 420, 868-874. doi: 10.1038/nature01323

Liu, J., Razani, B., Tang, S., Terman, B. I., Ware, J. A., and Lisanti, M. P. (1999). Angiogenesis activators and inhibitors differentially regulate caveolin-1 expression and caveolae formation in vascular endothelial cells. Angiogenesis inhibitors block vascular endothelial growth factor-induced down-regulation of caveolin-1. J. Biol. Chem. 274, 15781-15785. doi: 10.1074/jbc.274.22.15781

Liu, S. M., and Sundqvist, T. (1995). Effects of hydrogen peroxide and phorbol myristate acetate on endothelial transport and F-actin distribution. Exp. Cell Res. 217, 1-7. doi: 10.1006/excr.1995.1056

Lowe, D. J., and Raj, K. (2015). Quantitation of endothelial cell adhesiveness in vitro. J. Vis. Exp. 100:e52924. doi: 10.3791/52924

Lowe, D., and Raj, K. (2014). Premature aging induced by radiation exhibits proatherosclerotic effects mediated by epigenetic activation of CD44 expression. Aging Cell 13, 900-910. doi: 10.1111/acel.12253

Mackay, F., Loetscher, H., Stueber, D., Gehr, G., and Lesslauer, W. (1993). Tumor necrosis factor alpha (TNF-alpha)-induced cell adhesion to human endothelial cells is under dominant control of one TNF receptor type, TNF-R55. J. Exp. Med. 177, 1277-1286. doi: 10.1084/jem.177.5.1277

Mao, X. W., Favre, C. J., Fike, J. R., Kubinova, L., Anderson, E., Campbell-Beachler, M., et al. (2010). High-LET radiation-induced response of microvessels in the Hippocampus. Radiat. Res. 173, 486-493. doi: 10.1667/RR1728.1

Meeren, A. V., Bertho, J. M., Vandamme, M., and Gaugler, M. H. (1997). Ionizing radiation enhances IL- 6 and IL- 8 production by human endothelial cells. Mediators Inflamm. 6, 185-193. doi: 10.1080/09629359791677

Merl, J., Ueffing, M., Hauck, S. M., and von Toerne, C. (2012). Direct comparison of MS-based label-free and SILAC quantitative proteome profiling strategies in primary retinal Muller cells. Proteomics 12, 1902-1911. doi: 10.1002/pmic.201100549

Morais, C., Ebrahem, Q., Anand-Apte, B., and Parat, M. O. (2012). Altered angiogenesis in caveolin-1 gene-deficient mice is restored by ablation of endothelial nitric oxide synthase. Am. J. Pathol. 180, 1702-1714. doi: 10.1016/j.ajpath.2011.12.018

Moreels, M., de Saint-Georges, L., Vanhavere, F., and Baatout, S. (2012). "Stress and radiation responsiveness," in Stress Challenges and Immunity in Space: From Mechanisms to Monitoring, and Preventive Strategies, ed A. Choukèr (Heidelberg; New York, NY: Springer), 239-260.

Munzel, T., Sinning, C., Post, F., Warnholtz, A., and Schulz, E. (2008). Pathophysiology, diagnosis and prognostic implications of endothelial dysfunction. Ann. Med. 40, 180-196. doi: 10.1080/07853890701854702
Newhauser, W. D., and Durante, M. (2011). Assessing the risk of second malignancies after modern radiotherapy. Nat. Rev. Cancer 11, 438-448. doi: $10.1038 / \mathrm{nrc3} 069$

Nichols, R. C., Huh, S., Li, Z., and Rutenberg, M. (2015). Proton therapy for pancreatic cancer. World J. Gastrointest. Oncol. 7, 141-147. doi: 10.4251/wjgo.v7.i9.141

Pavlides, S., Gutierrez-Pajares, J. L., Iturrieta, J., Lisanti, M. P., and Frank, P. G. (2014). Endothelial caveolin-1 plays a major role in the development of atherosclerosis. Cell Tissue Res. 356, 147-157. doi: 10.1007/s00441-013-1767-7

Rombouts, C., Aerts, A., Beck, M., De Vos, W. H., Van Oostveldt, P., Benotmane, M. A., et al. (2013). Differential response to acute low dose radiation in primary and immortalized endothelial cells. Int. J. Radiat. Biol. 89, 841-850. doi: 10.3109/09553002.2013.806831

Rombouts, C., Aerts, A., Quintens, R., Baselet, B., El-Saghire, H., HarmsRingdahl, M., et al. (2014). Transcriptomic profiling suggests a role for IGFBP5 in premature senescence of endothelial cells after chronic low dose rate irradiation. Int. J. Radiat. Biol. 90, 560-574. doi: 10.3109/09553002.2014.905724

Sbaa, E., Frerart, F., and Feron, O. (2005). The double regulation of endothelial nitric oxide synthase by caveolae and caveolin: a paradox solved through the study of angiogenesis. Trends Cardiovasc. Med. 15, 157-162. doi: $10.1016 /$ j.tcm.2005.05.006

Scholz, M. (2003). "Effects of ion radiation on cells and tissues," in Radiation Effects on Polymers for Biological Use, eds H. Kausch, N. Anjum, Y. Chevolot, B. Gupta, D. Léonard, Mathieu, H. J. Pruitt, L. A. L. Ruiz-Taylor, and M. Scholz (Berlin; Heidelberg: Springer), 95-155.

Schuett, H., Luchtefeld, M., Grothusen, C., Grote, K., and Schieffer, B. (2009). How much is too much? Interleukin-6 and its signalling in atherosclerosis. Thromb. Haemost. 102, 215-222. doi: 10.1160/TH09-05-0297

Schultz-Hector, S., and Trott, K. R. (2007). Radiation-induced cardiovascular diseases: is the epidemiologic evidence compatible with the radiobiologic data? Int. J. Radiat. Oncol. Biol. Phys. 67, 10-18. doi: 10.1016/j.ijrobp.2006. 08.071

Schulz-Ertner, D., and Tsujii, H. (2007). Particle radiation therapy using proton and heavier ion beams. J. Clin. Oncol. 25, 953-964. doi: 10.1200/JCO.2006.09.7816

Sofia Vala, I., Martins, L. R., Imaizumi, N., Nunes, R. J., Rino, J., Kuonen, F., et al. (2010). Low doses of ionizing radiation promote tumor growth and metastasis by enhancing angiogenesis. PLOS ONE 5:e11222. doi: 10.1371/journal.pone.0011222

Sonveaux, P., Brouet, A., Havaux, X., Gregoire, V., Dessy, C., Balligand, J. L., et al. (2003). Irradiation-induced angiogenesis through the up-regulation of the nitric oxide pathway: implications for tumor radiotherapy. Cancer Res. 63, 1012-1019.

Soucy, K. G., Lim, H. K., Kim, J. H., Oh, Y., Attarzadeh, D. O., Sevinc, B., et al. (2011). HZE (5)(6)Fe-ion irradiation induces endothelial dysfunction in rat aorta: role of xanthine oxidase. Radiat. Res. 176, 474-485. doi: $10.1667 / R R 2598.1$

Stone, H. B., Coleman, C. N., Anscher, M. S., and McBride, W. H. (2003). Effects of radiation on normal tissue: consequences and mechanisms. Lancet Oncol. 4, 529-536. doi: 10.1016/S1470-2045(03)01191-4

Suetens, A., Konings, K., Moreels, M., Quintens, R., Verslegers, M., Soors, E., et al. (2016). Higher initial DNA damage and persistent cell cycle arrest after carbon ion irradiation compared to X-irradiation in prostate and colon cancer cells. Front. Oncol. 6:87. doi: 10.3389/fonc.2016. 00087

Sundqvist, T., and Liu, S. M. (1993). Hydrogen peroxide stimulates endocytosis in cultured bovine aortic endothelial cells. Acta Physiol. Scand. 149, 127-131. doi: 10.1111/j.1748-1716.1993.tb09604.x

Supek, F., Bosnjak, M., Skunca, N., and Smuc, T. (2011). REVIGO summarizes and visualizes long lists of gene ontology terms. PLoS ONE 6:e21800. doi: 10.1371/journal.pone.0021800

Takahashi, Y., Teshima, T., Kawaguchi, N., Hamada, Y., Mori, S., Madachi, A., et al. (2003). Heavy ion irradiation inhibits in vitro angiogenesis even at sublethal dose. Cancer Res. 63, 4253-4257.

Vita, J. A., and Keaney, J. F. Jr. (2002). Endothelial function: a barometer for cardiovascular risk? Circulation 106, 640-642. doi: 10.1161/01.CIR.0000028581.07992.56 
Widlansky, M. E., Gokce, N., Keaney, J. F. Jr., and Vita, J. A. (2003). The clinical implications of endothelial dysfunction. J. Am. Coll. Cardiol. 42, 1149-1160. doi: 10.1016/S0735-1097(03)00994-X

Widmer, R. J., and Lerman, A. (2014). Endothelial dysfunction and cardiovascular disease. Glob. Cardiol. Sci. Pract. 2014, 291-308. doi: 10.5339/gcsp.2014.43

Wilson, R. R. (1946). Radiological use of fast protons. Radiology 47, 487-491. doi: $10.1148 / 47.5 .487$

Wu, J., Liu, W., Bemis, A., Wang, E., Qiu, Y., Morris, E. A., et al. (2007). Comparative proteomic characterization of articular cartilage tissue from normal donors and patients with osteoarthritis. Arthritis Rheum 56, 3675-3684. doi: 10.1002/art.22876

Yentrapalli, R., Azimzadeh, O., Barjaktarovic, Z., Sarioglu, H., Wojcik, A., Harms-Ringdahl, M., et al. (2013a). Quantitative proteomic analysis reveals induction of premature senescence in human umbilical vein endothelial cells exposed to chronic low-dose rate gamma-radiation. Proteomics 13, 1096-1107. doi: 10.1002/pmic.201200463

Yentrapalli, R., Azimzadeh, O., Sriharshan, A., Malinowsky, K., Merl, J., Wojcik, A., et al. (2013b). The PI3K/Akt/mTOR pathway is implicated in the premature senescence of primary human endothelial cells exposed to chronic radiation. PLOS ONE 8:e70024. doi: 10.1371/journal.pone.0070024
Yu, T., Parks, B. W., Yu, S., Srivastava, R., Gupta, K., Wu, X., et al. (2011). Iron-ion radiation accelerates atherosclerosis in apolipoprotein E-deficient mice. Radiat. Res. 175, 766-773. doi: 10.1667/RR2482.1

Zhu, H., Yue, J., Pan, Z., Wu, H., Cheng, Y., Lu, H., et al. (2010). Involvement of Caveolin-1 in repair of DNA damage through both homologous recombination and non-homologous end joining. PLoS ONE 5:e12055. doi: 10.1371/journal.pone.0012055

Conflict of Interest Statement: The authors declare that the research was conducted in the absence of any commercial or financial relationships that could be construed as a potential conflict of interest.

Copyright ( 2017 Baselet, Azimzadeh, Erbeldinger, Bakshi, Dettmering, Janssen, Ktitareva, Lowe, Michaux, Quintens, Raj, Durante, Fournier, Benotmane, Baatout, Sonveaux, Tapio and Aerts. This is an open-access article distributed under the terms of the Creative Commons Attribution License (CC BY). The use, distribution or reproduction in other forums is permitted, provided the original author(s) or licensor are credited and that the original publication in this journal is cited, in accordance with accepted academic practice. No use, distribution or reproduction is permitted which does not comply with these terms. 